\title{
Caracterização da qualidade de néctar misto de carambola com hortelã ${ }^{1}$
}

\author{
Auryclennedy Calou de Araújo ${ }^{2}$, Flávio Luiz Honorato da Silva ${ }^{3}$, Josivanda Palmeira Gomes ${ }^{4}$, \\ Francilânia Batista da Silva ${ }^{5}$
}

Resumo: A elevada procura por produtos naturais e nutritivos nos últimos anos tem levado a indústria de alimentos ao desenvolvimento e elaboração de novos produtos que agreguem valor, gerem renda e estimule o cultivo, consumo e preservação de espécies pouco exploradas. Tendo em vista esses aspectos, o objetivo do presente estudo foi verificar o comportamento dos parâmetros físico-químicos de um néctar composto de polpa carambola e hortelã, em razão do fruto (carambola) ser pouco explorado regionalmente em escala comercial. Foram elaboradas três formulações e analisadas quanto ao o teor de água, açúcares (totais, não redutores e redutores), atividade de água, acidez titulável, vitamina $\mathrm{C}$, sólidos solúveis, $\mathrm{pH}$, cinzas e cor. As formulações resultaram em produtos com alta atividade de água, permaneceram dentro da faixa ácida $(\mathrm{pH} \leq 4,5)$ e atende aos parâmetros estabelecidos para néctares de frutas.

Palavras-chave: Bebida. Averrhoa carambola L.; Hortelã; Qualidade.

\section{Quality characterization of mixed nectar of star fruit with mint}

\begin{abstract}
The high demand for natural and nutritious products in recent years has led the food industry to develop and produce new products that add value, generate income and stimulate the cultivation, consumption and preservation of little exploited species. Considering these aspects, the objective of the present study was to evaluate the quality of a nectar composed of carambola and mint pulp, because star fruit is under exploited regionally on a commercial scale. Three formulations were tested and analyzed for water content, sugars (total, non-reducing and reducing), water activity, titratable acidity, vitamin $\mathrm{C}$, total soluble solids, $\mathrm{pH}$, ashes, and color. The formulations resulted in products with high water activity, maintained within the acidic range $(\mathrm{pH} \leq 4.5)$ and met the parameters established for fruit nectars.
\end{abstract}

Key words: Drink. Averrhoa carambola L.; Mint; Quality.

\footnotetext{
${ }^{1}$ Submetido em 01/03/2017 e aprovado em 06/04/2018

${ }^{2}$ Mestre em Engenharia Agrícola; Doutoranda, Universidade Federal de Campina Grande (UFCG), Programa de Pós-Graduação em Engenharia Agrícola, Campina Grande-PB, CEP: 58429-140; E-mail: auryclennedy@ hotmail.com

${ }^{3}$ Doutor em Engenharia de Alimentos; Professor Titular e Bolsista de Produtividade em Pesquisa do CNPq, Universidade Federal da Paraíba (UFPB), Programa de Pós-Graduação em Ciência e Tecnologia de Alimentos, João Pessoa-PB, CEP: 58429-140; E-mail: flavioluizh@yahoo.com.br

${ }^{3}$ Doutora em Engenharia de Alimentos; Professor Titular e Bolsista de Produtividade em Pesquisa do CNPq, Universidade Federal de Campina Grande (UFCG), Programa de Pós-Graduação em Engenharia Agrícola, Campina Grande-PB, CEP: 58429-140; E-mail: josivanda@gmail.com

${ }^{4}$ Mestre em Engenharia Agrícola; Doutoranda, Universidade Federal de Campina Grande (UFCG), Programa de Pós-Graduação em Engenharia de Processos, Campina Grande-PB, CEP: 58429-140; E-mail: francilania@live.com
} 


\section{Introdução}

Constantemente a indústria de alimentos tem buscado a inovação dos seus produtos, com a finalidade de agregar valor comercial e tornar alimentos de pouca procura atrativos e com características que supra as carências do organismo.

A caramboleira (Averrhoa carambola L.) é originária da Ásia e foi introduzida no Brasil em 1811, em Pernambuco no município de Olinda (Araújo e Minami, 2001). Atualmente está distribuída por todo o mundo, podendo ser encontrada na Austrália, Filipinas e outras ilhas do Pacífico Sul, América Central e do Sul, Caribe, África, Israel e em áreas subtropicais dos Estados Unidos (Lennox e Ragoonath, 1990). A caramboleira, segundo Saúco (1994) é considerada fruteira de grande potencial mercadológico devido, dentre outros fatores, ao rápido desenvolvimento, alta produtividade, sabor e aparência peculiares.

As formas de consumo da carambola são como fruta fresca ou sucos, geleias, compotas, doces caseiros e saladas (Bastos, 2004; Baldini et al., 1982; Jordão e Bonas, 1995). O fruto é fonte de vitaminas A e C, sendo rico em ácido oxálico. Seu sabor pode variar muito, de árvore para árvore e de fruto para fruto, mas costuma ser adocicado, quando amadurece e um tanto ácido e adstringente, quando ainda verde. Seu suco, além de possuir um delicioso sabor, é utilizado no combate a disenteria, febres, escorbuto e, devido à grande quantidade de ácido oxálico, é ainda utilizada pela medicina popular no tratamento de afecções renais (Teixeira et al., 2001).

A hortelã (Mentha arvenisis), é largamente utilizada na indústria farmacêutica devido aos efeitos anti-reumáticos, diuréticos e antiespasmódicos. O óleo essencial extraído da hortelã é rico em monoterpenos, o que permite sua aplicação em diversos setores industriais. $\mathrm{Na}$ culinária, além da aplicação de folhas frescas e desidratadas em diversos pratos, contamos com os licores saborosos e marcantes (Lange e Ankami, 2013; Rosa et al., 2011).

A proposta de produção de néctares a partir de polpas de frutas é uma solução bastante plausível, principalmente quando combinamos duas ou mais frutas (blends) (Damiani et al., 2011). Néctar é a bebida não fermentada, obtida das partes comestíveis de vegetais ou de seus extratos diluídos em água potável, adicionado de açúcar e destinado ao consumo direto. Associando a alta produção e a qualidade da carambola e a possibilidade de incorporar a mesma nos processamentos de alimentos, juntamente com a hortelã com seu sabor marcante e agradável, que pode conferir sabor refrescante a bebida, somar nutrientes e mascarar o ácido da carambola, facilitando a aceitabilidade por parte do consumidor, o objetivo deste trabalho foi avaliar a qualidade de diferentes formulações de néctares obtidos a partir da carambola com hortelã.

\section{Material e Métodos}

Os frutos de carambola e a hortelã utilizados no presente trabalho foram adquiridos de pequenos produtores rurais da cidade de Juazeiro do Norte-CE, estes foram selecionados quanto a aparência, ausência de injúrias e maturação, os mesmos foram lavados em água corrente e sanitizados com solução de hipoclorito de sódio a 100ppm por dez minutos.

A carambola foi despolpada manualmente com auxílio de facas de aço inoxidável, logo após, triturada em liquidificador industrial, foi acondicionada em sacos de polietileno $( \pm 100 \mathrm{~g})$ e armazenada em freezer a $-18^{\circ} \mathrm{C}$. As folhas de hortelã foram imersas em água clorada a 100ppm/10min, em seguida escorridas em peneira de nylon e postas bob água corrente para retirada do excesso de cloro. Foram pesados $200 \mathrm{~g}$ de folhas e colocadas em $200 \mathrm{~mL}$ de água mineral fervente. $\mathrm{O}$ recipiente foi abafado e deixado em repouso por uma hora, em seguida a infusão foi submetida a peneira para retirada das folhas e o liquido reservado. Foram pesados $300 \mathrm{~g}$ de polpa da carambola descongelada a temperatura ambiente e colocado em um recipiente doméstico de aço inox previamente higienizado, foram adicionados $600 \mathrm{~mL}$ de água mineral e $60 \mathrm{~g}$ de açúcar cristal, a mistura foi homogeneizada obtendo-se o néctar da carambola.

Em três recipientes domésticos de aço inox previamente higienizados, foram realizadas 3 formulações de néctar conforme a Tabela 1, onde a formulação 1 corresponde a $200 \mathrm{~mL}(100 \%)$ de puro néctar de carambola, a formulação 2 corresponde a $140 \mathrm{~mL}(70 \%)$ de néctar de carambola e $60 \mathrm{~mL}(30 \%)$ da infusão da hortelã e a formulação 3 corresponde a $100 \mathrm{~mL}(50 \%)$ de néctar de carambola e $100 \mathrm{~mL}(50 \%)$ de infusão da hortelã. Os recipientes foram levados a banho- 
maria $90^{\circ} \mathrm{C}$ por $10 \mathrm{~min}$, envasados em recipientes de polietileno de alta densidade, tampados e mantido sob refrigeração $\left(5-7^{\circ} \mathrm{C}\right)$ para posterior caracterização físico-química.

Tabela 1 Formulações de néctares mistos de carambola e hortelã

\begin{tabular}{ccc}
\hline Formulacão & Carambola (\%) & Hortelã (\%) \\
\hline F1 & 100 & 0 \\
F2 & 70 & 30 \\
F3 & 50 & 50 \\
\hline
\end{tabular}

Realizou-se as seguintes determinações: $\mathrm{pH}$ (método eletrométrico), sólidos solúveis (SS) em ${ }^{\circ}$ Brix (método refratométrico), acidez titulável (AT- g de ácido cítrico/100g de polpa) (método titulométrico), ácido ascórbico (mg de ácido ascórbico/100g de polpa), açúcares redutores (\% glicose), totais (\% glicose + sacarose) e cinzas ( $\%$ cinzas). Todas estas determinações foram realizadas de acordo com as normas do Instituto Adolfo Lutz (IAL, 2008). As amostras foram analisadas quanto à cor com auxílio do colorímetro Mini Scan Hunter Lab, para os parâmetros $L^{*}$, que mede a luminosidade, a*, intensidade de vermelho e $b^{*}$, intensidade de amarelo. Determinou-se a atividade de água utilizando-se o equipamento Aqualab CX-2T Decagon, na temperatura de $25^{\circ} \mathrm{C}$.

Para tratamentos dos dados utilizou-se o programa ASSISTAT versão 7.7 beta. Os mesmos foram submetidos à análise de variância (ANOVA) e o delineamento experimental empregado foi o inteiramente casualizado (DIC), o teste de Tukey ao nível de 5\% de significância foi aplicado para obter a comparação de médias.

\section{Resultados e Discussão}

De acordo com a Tabela 2, pode-se verificar que os valores de teor de água das amostras diferiram estatisticamente; verifica-se que a formulação F1 apresentou-se com o teor de água superior a F2 e F3, de modo que quanto menor é a proporção de carambola e maior a da hortelã, menor é o teor de água. Valores inferiores ao encontrado para os néctares de carambola com hortelã foram relatados por Moura et al. (2014) ao caracterizarem néctares de goiaba-tomate, em diferentes concentrações, verificaram valores entre 81,77 a $80,89 \%$, considerando o teor de água elevado. A atividade de água (aw) da formulação 1 diferiu significativamente das demais, indicando que o aumento da concentração da polpa de carambola reduziu significativamente a atividade de água do produto. CASTRO et al. (2014) ao produzirem néctares a partir da adição de diferentes proporções de polpa de ceriguela e de abacaxi, obtiveram valores de 0,99 para as três formulações.

Tabela 2 Aspectos da qualidade de diferentes formulações de néctar misto de carambola com hortelã

\begin{tabular}{lccc}
\hline \multirow{2}{*}{ Parâmetros } & \multicolumn{3}{c}{ Formulações } \\
\cline { 2 - 4 } & F1 & F2 & F3 \\
\hline pH & $3,74 \mathrm{~d} \pm 0,02$ & $4,02 \mathrm{c} \pm 0,00$ & $4,43 \mathrm{~b} \pm 0,02$ \\
Teor de água (\%) & $94,42 \mathrm{a} \pm 0,08$ & $94,54 \mathrm{ab} \pm 0,08$ & $94,85 \mathrm{bc} \pm 0,19$ \\
SS ( ${ }^{\circ}$ Brix) & $13,13 \mathrm{a} \pm 0,00$ & $12,89 \mathrm{a} \pm 0,00$ & $13,33 \mathrm{a} \pm 0,00$ \\
Acidez titulável(g ác. Cítrico/100g) & $1,52 \mathrm{a} \pm 0,01$ & $1,33 \mathrm{~b} \pm 0,00$ & $1,02 \mathrm{c} \pm 0,00$ \\
Vitamina C (mg/100g) & $37,34 \mathrm{a} \pm 0,16$ & $21,63 \mathrm{c} \pm 0,13$ & $21,91 \mathrm{c} \pm 0,16$ \\
Cinzas $(\%)$ & $0,48 \mathrm{~b} \pm 0,03$ & $0,43 \mathrm{a} \pm 0,01$ & $0,35 \mathrm{c} \pm 0,02$ \\
Atividade de água (aw) & $0,987 \mathrm{a} \pm 0,00$ & $0,983 \mathrm{~b} \pm 0,00$ & $0,980 \mathrm{~b} \pm 0,00$ \\
Açucares redutores $(\%$ glicose) & $7,75 \mathrm{c} \pm 0,01$ & $10,61 \mathrm{a} \pm 0,00$ & $13,96 \mathrm{a} \pm 0,16$ \\
Açucares totais $(\%$ glicose + sacarose) & $29,20 \mathrm{~d} \pm 0,19$ & $32,25 \mathrm{c} \pm 0,23$ & $36,27 \mathrm{~b} \pm 0,39$ \\
Luminosidade $(\mathrm{L} *)$ & $36,22 \mathrm{a} \pm 0,06$ & $45,16 \mathrm{c} \pm 0,03$ & $46,60 \mathrm{~b} \pm 0,04$ \\
Intensidade de vermelho (+a*) & $1,14 \mathrm{c} \pm 0,01$ & $1,86 \mathrm{a} \pm 0,01$ & $1,19 \mathrm{~b} \pm 0,01$ \\
Intensidade de amarelo (+b*) & $83,52 \mathrm{a} \pm 0,17$ & $73,86 \mathrm{~b} \pm 0,08$ & $65,72 \mathrm{~b} \pm 0,10$ \\
\hline Médias seguidas pelas mesmas letras minúsculas na linha não diferem estatisticamente pelo teste de Tukey a 5\% de probabilidade. F1 - \\
100\% carambola; F2 - 70\% carambola + 30\% hortelã; F3 - 50\% carambola $+50 \%$ hortelã.
\end{tabular}

Quanto ao $\mathrm{pH}$ pode-se observar que a amostra F3 $(50 \%$ de carambola $+50 \%$ de hortelã) apresentou-se com o valor superior as demais, ou seja, o pH do néctar foi se tornando menos ácido com o aumento percentual da hortelã. $\mathrm{O}$ néctar que se apresentou mais ácido foi o constituído de $100 \%$ carambola (F1). Valor inferior do $\mathrm{pH}$ foi encontrado por Bagano et al. (2013) ao caracterizarem um néctar de água de coco com maracujá (pH- 3,10). De acordo com Alcântara et 
al. (2007), os valores de pH abaixo de 4,5 são interessantes para a indústria alimentícia, já que inibe o desenvolvimento e crescimento de microrganismos, permitindo assim a conservação do produto processado.

Para a acidez titulável (AT) os teores variaram de $1,02-1,52 \%$. Todos os valores de AT diferiram significativamente entre si, de modo que, à medida que aumentava a concentração de hortelã na formulação o teor de acidez foi reduzido. NEVES et al, (2011) obtiveram como resultados 0,82 e 1,89 de AT pata blends de abacaxi + carambola e Maracujá + carambola, respectivamente. Souza et al. (2012) encontraram valor de $0,27 \%$ de acidez para o néctar preparado com a mistura $30 \%$ de polpa de kiwi, $61 \%$ de água e 9\% de açúcar. Os sólidos solúveis (SS) expressos em ${ }^{\circ}$ Brix apresentou uma variação de 12,89 a $13,33^{\circ}$ Brix, porém, não apresentou diferença estatística. Abreu et al. (2011) ao caracterizarem néctares de ameixa adoçados na proporção de $12,5 \%$ de açúcar (FA) e a mesma proporção de mel para a $\mathrm{FB}$, relatam valores na faixa de 14,4 e $12,2^{\circ}$ Brix, respectivamente. Valores superiores foram reportados por Morzelle et al. (2009) ao caracterizarem néctares misto de maracujá e ata (Annona squamosa L.), entre 15 e $16^{\circ}$ Brix.

Os teores de açúcares redutores e totais apresentaram acentuadas diferenças entre as formulações, o que se justifica pelos diferentes percentuais de polpa, porém essa diferença não apresentou um comportamento delineado, seguindo uma escala crescente ou decrescente. Houve um aumento dos açúcares totais com a redução da carambola e o aumento da hortelã.

Os teores de vitamina $\mathrm{C}$, relativos aos três tipos de formulações avaliadas, mostraram-se bastante inferiores ao obtido por Prati et al. (2002) ao estudar a carambola fresca. Os néctares apresentaram teores variando de 37,34 a 21,91, sendo que as formulações F2 e F3 não diferiram entre si; esses teores relativamente baixos podem ser decorrentes do fato de que a polpa de carambola foi armazenada sob refrigeração antes da elaboração e análises dos néctares e esse composto que é de fácil degradação, ter se degradado no período em que ficou armazenada, cerca de três semanas. O teor de cinzas encontrado variou de 0,48 a $0,35 \%$; pode-se observar que a amostra composta de $100 \%$ de carambola apresentou teor superior às demais, sendo que todas as formulações diferiram entre si. Teores similares foram reportados por Silva et al. (2013) ao elaborarem diferentes formulações de blends compostos de mamão e figo da índia, variando de $0,34-0,47 \%$.

Os valores da Luminosidade (L*) aumentaram com a adição da hortelã, constatando-se diferença estatística significativa entre as formulações elaboradas. A Luminosidade do néctar de $100 \%$ de carambola (F1) foi inferior aos valores das Formulações 2 e 3, e F3 apresentase como a mais escura, pois mostrou o menor valor para a luminosidade; intensidade de vermelho $\left(+\mathrm{a}^{*}\right)$ não apresentou uma escala crescente ou decrescente dos valores, tornando-se assim indefinido, variando de 1,86 a 1,14. Para a intensidade de amarelo $\left(+b^{*}\right)$ percebe-se que ocorreu uma redução significativa de+b* com o aumento da concentração da hortelã, indicando que a intensidade de amarelo foi menor na formulação $\mathrm{F} 3$, que consta de $50 \%$ de carambola e 50\% de hortelã, indicando que a adição deste reduz a coloração amarela, mas aumenta a coloração esverdeada.

\section{Conclusão}

Conclui-se que as formulações do néctar misto de carambola + infusão da hortelã apresentaram boas características para $\mathrm{o}$ consumo, visto que a cor, a julgar pela intensidade de amarelo pode conferir uma ótima aceitação do produto;

Os valores de $\mathrm{pH}$ apresentaram-se numa faixa considerada segura, tendo em vista o alto teor de água e atividade de água do produto, o que propicia as contaminações microbiológicas;

$\mathrm{O}$ teor de vitamina $\mathrm{C}$ presente é considerado bom, visto que a adição de água diminui o poder antioxidante da fruta inatura;

Conclui-se ainda além das justificativas supracitadas que, a produção de néctar misto de carambola e infusão da hortelã é um processo simples, seguro que enaltece a potencialidade de frutas que não são aproveitadas em algumas regiões, gerando renda e agregando valor a cultura.

\section{Referências}

Alcântara, S. R.; Almeida, F. A. C.; Silva, F. L. H. Emprego do bagaço seco do pedúnculo do caju para posterior utilização em processo de fermentação semissólida. Revista Brasileira de 
Produtos Agroindustriais, v.9, n.2, p.137-142, 2007. http://deag.ufcg.edu.br/rbpa/rev92/Art925.pdf

Araujo, P. S. R.; Minami, K. Seleção de caramboleiras pelas características biométricas e físico-químicas dos frutos. Scientia agrícola, v.58, n.1, p. 91-99, 2001. http://dx.doi.org/10.1590/S0103-90162001000100015

Bagano, J. S.; Gomes, R. B.; Cardoso, R. L.; Tavares, T. de Q.; Santos, D. B. dos. Aceitação sensorial e caracterização físico-química de néctar de água de coco com maracujá. Enciclopédia Biosfera, v.9, n.16, p.38-44, 2013. http://conhecer.org.br/enciclop/2013a/agrarias/aceitacao $\% 20$ sensorial.pdf

Baldini, V. L. S.; Draeta, I. S.; Nomura, E. H. Avaliação bioquímica de carambola (Averrhoa carambola L.). Coletânea do Instituto de Tecnologia de Alimentos, v.12, p.283-291, 1982.

Bastos, D. C. A cultura da carambola. Revista Brasileira de Fruticultura, v.26, n.2, p.193$384, \quad 2004$. http://dx.doi.org/10.1590/S010029452004000200001

Castro, D. S.; Nunes, J. S.; Silva, F. B. da; Oliveira, T. K. B. de; Silva, L. M. de M. Desenvolvimento e avaliação físico-química de néctar misto de abacaxi (Ananas comosus) e Seriguela (Spondias purpurea). Revista Verde de Agroecologia e Desenvolvimento Sustentável, v.9, n.1, p.06-09, 2014. http://gvaa.com.br/revista/index.php/RVADS/article/view $\underline{12588}$

Damiani, C.; Silva, F. A. da; Amorim, C. C. de M.; Silva, S. T. P.; Bastos, I. M.; Asquieri, E. R.; Vera, R. Néctar misto de cajá-manga com hortelã: Caracterização química, microbiológica e sensorial. Revista Brasileira de Produtos Agroindustriais, v.13, p.301-309, 2011. http://doi:10.15871/1517-8595/rbpa.v13n3p301$\underline{309}$

Jordão, P. R.; Bonnas, D. S. Aproveitamento industrial da carambola. Alimentos/Qualidade \& Produtividade, n.7, p.28-29, 1995.

Lange, B. M.; Ahkami, A. Metabolic engineering of plantmo noterpenes, sesquiterpenes $\mathrm{e}$ diterpenes-current stats and future opportunities. Plant Biotechnol Journal, v.11, n.2, p.169-196, 2013. http://doi.org/10.1111/pbi.12022
Lennox, A.; Ragoonath, J. Carambola and bilimbi. Fruits, v.45, n.5, p.497-501, 1990. http://agris.fao.org/agrissearch/search.do?recordID=FR9304991

Morzelle, M. C.; Souza, E. C.; Assumpção, C. F.; Flores, J. C. J.; Oliveira, K. A. M. Agregação de valor a frutos de ata através do desenvolvimento de néctar misto de maracujá (Passiflora edulis Sims) e ata (Annona squamosa L.). Alimentos Nutricionais, v.20, n.3, p.389-393, 2009. http://serv-

bib.fcfar.unesp.br/seer/index.php/alimentos/article/viewA rticle/1132

Moura, R. L., Figueirêdo, R. M. F., Queiroz, A. J. M. Processamento e caracterização físicoquímica de néctares goiaba-tomate. Revista Verde, v .9, n.3, p 69-75, 2014. http://gvaa.com.br/revista/index.php/RVADS/article/view $\underline{12828}$

Neves, L. C.; Benedette, R. M.; Tosin, J. M.; Coelho, P. C. S.; Silva, V. X.; Prill, M. A. S.; Roberto, S. R: Produção de blends a partir de frutos tropicais e nativos da amazônia. Revista Brasileira de Fruticultura, v.33, n.1, p.187197, 2011. http://dx.doi.org/10.1590/S010029452011005000023

Rosa, N. C.; Trintim, L. T.; Corrêa, R. C. G.; Vieira, A. M. S.; Bergamosco, R: Elaboração de geléia de abacaxi com hortelã zero açúcar: processamento, parâmetros físico-químicos e análise sensorial. Revista Tecnológica, v.13, n.1, p.83-89, 2011. http://dx.doi.org/10.4025/revtecnol.v0i0.14994

Saúco, V. G. Possibilities of no-citrus tropical fruit in the Mediterranean. Acta Horticulturae, n.365, v.1, p.25-41, 1994. http://doi.org/10.17660/ActaHortic.1994.365.2

Silva, S. F. da; Figueirêdo, R. M. F.; Queiroz, A. J. de M.; Lemos, D. M.; Lima, J. C. B. Caracterização de blends de mamão formosa e figo-da-índia. Revista Verde, v.7, n.3, p.202206 , 2013. http://gvaa.com.br/revista/index.php/RVADS/article/view $\underline{12273}$

Teixeira, H. A. T.; Durigan, L. C. D.; Silva, J. A. A. Caracterização pós-colheita de seis cultivares de carambola (Averrhoa carambola L.). Revista Brasileira de Fruticultura, v.23, n.3, p.546-550, 2001. http://dx.doi.org/10.1590/S0100-29452001000300019 